Ther Adv Gastroenterol

(2013) 6(5) 344-357

DOI: $10.1177 /$

$1756283 \times 13491798$

(c) The Author(s), 2013 Reprints and permissions: http://www.sagepub.co.uk/ journalsPermissions.nav

\title{
A 9-year evaluation of temporal trends in alosetron postmarketing safety under the risk management program
}

\author{
Kenneth Tong, Jean Paul Nicandro, Reshma Shringarpure, Emil Chuang and Lin Chang
}

\begin{abstract}
Objectives: Adverse events (AEs) of ischemic colitis (IC) and complications of constipation $(\mathrm{CoC})$ associated with alosetron are rare and have been adjudicated during the first 5.5 years of the risk management program (RMP); however, changes in incidence rates relative to reductions in AE reports and increases in alosetron prescriptions over the 9-year RMP have not been evaluated. The authors aim to evaluate temporal trends in alosetron postmarketing safety over the 9-year RMP.

Methods: The alosetron safety database was searched to identify cases of IC, CoC, and related AEs from 20 November 2002 to 31 December 2011. Adjudication of IC and CoC cases were based on US Food and Drug Administration-defined criteria. Incidence rates were calculated using the number of AEs and alosetron prescriptions lexpressed as cases/1000 patient-years exposure).

Results: A total of 29 cases were adjudicated as probable/possible IC and 7 cases were adjudicated as CoC. Cumulative adjudicated incidence rate of IC 1.03 cases/1000 patientyears) is low and stable, while that of $\mathrm{CoC}(0.25$ cases/1000 patient-years) is low, declining progressively over time. Decreases in the incidence rates of potential symptoms of IC labdominal pain with bloody diarrhea/hematochezia) and CoC (constipation) were also observed. Conclusions: Over the 9-year RMP period, incidence rates of IC and $\mathrm{CoC}$ remain rare. Substantial reductions over time were observed in the incidence of $\mathrm{CoC}$ and in symptoms suggestive of IC or $\mathrm{CoC}$, while IC incidence has been stable at approximately 1.0 case/1000 patient-years. Decreases in AEs and serious outcomes associated with IC and $\mathrm{CoC}$ since the reintroduction of alosetron are likely attributable to the RMP.
\end{abstract}

Keywords: alosetron, complications of constipation, ischemic colitis, postmarketing, risk evaluation and mitigation strategy, risk management program, safety, severe diarrheapredominant irritable bowel syndrome

Correspondence to: Lin Chang, MD

Oppenheimer Family Center for Neurobiology of Stress, Division of Digestive Diseases, David Geffen School of Medicine at UCLA, 10833 Le Conte Avenue, CHS 42-210, Los Angeles, CA 90095-7378, USA

linchangRmednet.ucla.edu Kenneth Tong, PharmD Medical Affairs 360, San Diego, CA, USA

Jean Paul Nicandro, PharmD Reshma Shringarpure, PhD Emil Chuang, MD

Prometheus Laboratories Inc., San Diego, CA, USA

\section{Introduction}

Alosetron is a selective $5-\mathrm{HT}_{3}$ receptor antagonist currently approved for the treatment of women with severe diarrhea-predominant irritable bowel syndrome (IBS-D), who have had an inadequate response to conventional therapy [Prometheus Laboratories Inc., 2010]. Results from clinical studies have demonstrated significant efficacy for alosetron in IBS, particularly in improving fecal urgency, stool frequency, and consistency [Camilleri et al. 2000, 2001]. Moreover, in female patients with severe IBS-D, alosetron has been shown to improve global symptoms of IBS and provide adequate relief of IBS pain and discomfort [Lembo et al. 2004; Krause et al. 2007; Chey et al. 2004]. Based on the collective evidence on its efficacy in clinical trials, alosetron was initially approved in the USA in February 2000.

Reported adverse events (AEs) that occurred at a greater frequency in IBS patients receiving alosetron $1 \mathrm{mg}$ twice daily than in placebo-treated patients included constipation, abdominal pain 
and discomfort, and nausea. In these clinical trials, alosetron was associated with infrequent but serious gastrointestinal AEs of ischemic colitis (IC) and complications of constipation ( $\mathrm{CoC}$ ). The cumulative incidence of IC in female patients with IBS treated with alosetron was $0.2 \%$ through 3 months and $0.3 \%$ through 6 months [Prometheus Laboratories Inc., 2010]. Overall, a statistically significant increase in the incidence of IC was observed from clinical trials in alosetrontreated patients compared with placebo $(0.15 \%$ versus $0.00 \%, p=0.03$ ); however, no significant differences were seen with CoC [Chang et al. 2006]. Due to postmarketing reports of IC and $\mathrm{CoC}$ following its approval, alosetron was voluntarily withdrawn by GlaxoSmithKline only 9 months later. In November 2002, in response to requests from individuals with IBS and patient advocacy groups, the US Food and Drug Administration (FDA) and GlaxoSmithKline reached an agreement to reintroduce alosetron to the US market under a risk management program (RMP) [FDA, 2002].

The alosetron RMP was created based on the FDA's risk minimization action plan (RiskMAP) with the goal of mitigating serious outcomes of IC and $\mathrm{CoC}$ [FDA, 2005]. The various elements of the alosetron RMP were intended to educate physicians and patients on the risks and benefits of treatment, signs and symptoms of IC and $\mathrm{CoC}$, and appropriate management of these AEs, if they occur. The RMP consisted of the prescribing program for Lotronex ${ }^{\mathrm{TM}}$, a medication guide, and patient follow-up survey. Also, the alosetron indication was restricted to female patients with chronic, severe IBS-D, and recommended that patients meet at least one of three severity criteria: (a) frequent and severe abdominal pain/discomfort; (b) frequent bowel urgency or fecal incontinence; and/or (c) disability or restriction of daily activities due to IBS symptoms [Miller et al. 2006]. The RMP has since been converted to a risk evaluation and mitigation strategy (REMS) program in September 2010 [FDA, 2013]. Hereafter in this report, the term RMP is used globally to refer to either FDA-mandated RiskMAP (November 2002-August 2010), or REMS (September 2010-present) program for risk management.

An analysis of postmarketing safety data with alosetron under the RMP was previously performed by Chang and colleagues, who evaluated the incidence, clinical characteristics, and outcomes of IC and CoC from November 2002 to
June 2008 [Chang et al. 2010]. During this period, a total of 29,072 patients received 203,939 prescriptions of alosetron. Following FDA-defined adjudication criteria, the incidence of probable/ possible cases of IC and $\mathrm{CoC}$ were found to be rare in occurrence, as supported by incidence rates of 0.95 cases/1000 patient-years for IC and 0.36 cases per 1000 patient-years for $\mathrm{CoC}$. These incidence rates were similar to those observed for IC and $\mathrm{CoC}$ during the initial postmarketing surveillance period up to February 2004 [Chang et al. 2006]. No surgeries or deaths were observed in patients with probable/possible IC and CoC. Chang and colleagues demonstrated that the RMP was effective in mitigating serious outcomes of IC and $\mathrm{CoC}$ associated with alosetron during the initial 5.5 years since its implementation [Chang et al. 2010].

Following the reintroduction of alosetron under the RMP in November 2002, alosetron prescriptions were initially low but have increased over time. An estimated 340,000 prescriptions corresponding to approximately 28,000 patient-years of drug exposure have been recorded under the RMP. Therefore, the aims of this report are: (a) to provide a 9-year analysis of the incidence and characteristics of IC and CoC cases in the postmarketing population of patients with severe IBS-D treated with alosetron under the RMP; (b) to evaluate temporal trends (i.e. changes over time) in the incidence rates of probable/possible IC, CoC, and other clinically relevant AEs over the 9-year period of the RMP; (c) to assess the effectiveness of the alosetron RMP in mitigating clinically relevant AEs (i.e. abdominal pain accompanied by hematochezia or bloody diarrhea and constipation), and serious outcomes associated with IC and CoC (e.g. death, surgery, transfusion, hospitalization); (d) to explore clinical characteristics and presentation associated with IC and $\mathrm{CoC}$.

\section{Materials and methods}

The methodology for this analysis has been previously described in detail by Chang and colleagues [Chang et al. 2010]. A summary of this methodology, including any differences with the present analysis, is provided below.

\section{Data sources}

The alosetron safety database, which contained only postmarketing $\mathrm{AE}$ reports for patients who received alosetron under the RMP, was used to 
identify potential cases of IC and CoC. AEs of IC and $\mathrm{CoC}$ from clinical trials were not included in this analysis. Potential cases for the current analysis were extracted during the period from 20 November 2002 to 31 December 2011. Demographic data for patients including age, presenting symptoms, concomitant medications, concurrent medical conditions, and AE-related information (i.e. time to onset, duration of illness, hospitalization, and outcomes) were obtained from FDA MedWatch forms.

\section{Selection, screening, and adjudication of potential cases of IC and CoC}

The following keywords from the Medical Dictionary for Regulatory Activities (MedDRA), version 10.1, were used to search the alosetron safety database to identify all potential cases of IC: colitis ischemic, intestinal ischemia, and colitis as a serious AE. A search for MedDRA terms that may have described symptoms of potential IC cases was also performed, including abdominal pain, abdominal discomfort, gastrointestinal pain, gastrointestinal discomfort, hematochezia, bloody diarrhea, and diarrhea hemorrhagic. Potential IC cases were adjudicated to determine if there was substantial evidence to support an IC diagnosis and were deemed either probable, possible, or unlikely IC according to the criteria established during discussions between the FDA and the sponsor in 2002 [FDA, 2002].

MedDRA terms determined by the FDA and the sponsor to be potential diagnoses for $\mathrm{CoC}$ were obstruction, perforation, intestinal ulceration, toxic megacolon, ileus, and impaction resulting in hospital admissions (i.e. fecal impaction as a serious AE) [FDA, 2002]. To account for the difference in AE-coding conventions used by the former sponsor, MedDRA search terms for the present analysis included colonic stenosis, gastrointestinal pain, ileal perforation, ileus, ileus paralytic, intestinal obstruction, intestinal perforation, impaired gastric emptying, large intestinal perforation, lower gastrointestinal hemorrhage, small intestinal obstruction, and serious AEs of bowel obstruction, megacolon, fecal impaction, and fecal perforation. Criteria for $\mathrm{CoC}$ included medical history, reported diagnoses, and supportive test results that were consistent with one of the above listed diagnoses of CoC.

Two gastroenterologists (LC and EC) independently reviewed and evaluated all potential cases of IC or CoC identified from the alosetron safety database. One of the reviewers (LC) was involved in previous adjudications of the safety data [Chang et al. 2006, 2010].

\section{Data analyses}

The annual and total number of alosetron prescriptions and patients receiving prescriptions were monitored under the RMP. Each prescription was considered to represent 1 month of alosetron use to determine the extent of exposure in the postmarketing population. Incidence rates were calculated (cases per 1000 patient-years of exposure) for IC and $\mathrm{CoC}$ for the period prior to withdrawal and the period after reintroduction of alosetron to the US market. The reported incidence rate includes all potential IC and $\mathrm{CoC}$ cases (pre-adjudication) identified from the alosetron safety database using the search strategy described above. The adjudicated incidence rate includes all reported cases of IC and $\mathrm{CoC}$ that were determined to be probable or possible for the diagnoses of IC and CoC. Cumulative incidence rates for IC, CoC, and other clinically relevant AEs were calculated for each year beginning with 2003 (which included approximately 6 weeks of data from 2002: 20 November-31 December) through to the end of 2011 using reported and adjudicated cases. Cumulative incidence rate was calculated by the accumulated IC or CoC cases divided by the number of cumulative prescriptions during the 9-year period.

Postmarketing AE reports of abdominal pain and hematochezia or bloody diarrhea were queried from the safety database over the 9-year period after reintroduction to evaluate the reported incidence rate for potential symptoms indicative of IC. Similarly, AEs of constipation were queried during this period to evaluate the reported incidence rate of potential symptoms indicative of CoC. Additional clinical data (i.e. age, time to onset, duration of symptoms, alosetron dosage, comorbidities, concomitant medications, and outcomes) available from probable/possible IC and $\mathrm{CoC}$ cases were extracted from the FDA MedWatch Forms. The characteristics, demographics, clinical symptoms, and outcomes for all probable or possible cases of IC and CoC were summarized overall and by time period (before alosetron withdrawal and after reintroduction under RMP). In addition, characteristics of the probable/possible IC cases were examined for the following subgroups to investigate clinically 
Table 1. Reported and adjudicated incidence rates for ischemic colitis and complications of constipation for patients treated with alosetron (calculated per 1000 patient-years).

\begin{tabular}{|c|c|c|}
\hline & $\begin{array}{l}\text { Before June } 2002 \text { (before } \\
\text { reintroduction/prior to the } \\
\text { risk management program)* }\end{array}$ & $\begin{array}{l}\text { November 2002-December } \\
2011 \text { (reintroduction under the } \\
\text { risk management program) }\end{array}$ \\
\hline Number of prescriptions & 586,000 & 341,784 \\
\hline $\begin{array}{l}\text { Patient-years of alosetron } \\
\text { exposure } \$\end{array}$ & 48,829 & 28,084 \\
\hline \multicolumn{3}{|l|}{ Ischemic colitis } \\
\hline $\begin{array}{l}\text { Reported incidence rate } \\
\text { (pre-adjudication) }\end{array}$ & 1.70 & 1.53 \\
\hline $\begin{array}{l}\text { Adjudicated incidence rate } \\
\text { (probable/possible) }\end{array}$ & 0.96 & 1.03 \\
\hline \multicolumn{3}{|l|}{ Complications of constipation } \\
\hline $\begin{array}{l}\text { Reported incidence rate } \\
\text { (pre-adjudication) }\end{array}$ & 2.00 & 0.93 \\
\hline Adjudicated incidence rate & 0.59 & 0.25 \\
\hline
\end{tabular}

meaningful trends: age group ( $\leq 50$ years, $>50$ years); time to onset of IC ( $\leq 120$ days, earlyonset; >120 days, late-onset); duration of IC symptoms ( $\leq 5$ days, short; $>5$ days, long), and hospitalization status (hospitalized, not hospitalized). Since this study was based on postmarketing case reports and not designed to test any statistical hypothesis, only descriptive statistics (e.g. means, counts and percentages) of the data are presented and summarized.

\section{Results}

During the 9-year postmarketing period under the RMP, a total of approximately 32,000 patients used 341,784 prescriptions of alosetron, corresponding to an estimated 28,084 patient-years of alosetron exposure. In total, 43 potential cases of IC and 26 potential cases of $\mathrm{CoC}$ were identified for further analysis and adjudication. Of these, 29 probable or possible cases of IC and 7 cases of $\mathrm{CoC}$ were identified, which correspond to adjudicated incidence rates of 1.03 cases $/ 1000$ patient-years and 0.25 cases/1000 patient-years, respectively. The overall incidence rates for IC and $\mathrm{CoC}$ associated with alosetron over the 9-year period of the RMP are compared with the rates observed for the period prior to reintroduction in Table 1.

\section{IC cases}

The 29 cases of probable/possible IC all occurred in women with a median age of 55 years taking a median total daily dose of alosetron $1 \mathrm{mg}$. Median time to onset of IC symptoms was 114 days with a median duration of 6 days. With respect to the clinical presentation of probable/possible IC cases, the most common symptoms were abdominal pain $(90 \%)$ followed by hematochezia or bloody diarrhea (83\%), and nausea/vomiting (38\%), with abdominal pain accompanied by hematochezia reported in $72 \%$ of cases. Constipation at presentation was observed in $21 \%$ of IC cases. All probable/possible cases of IC were confirmed by healthcare providers, with biopsy findings consistent with IC obtained in $76 \%$ of cases. Additional details regarding demographics, clinical characteristics, and outcomes of these probable/possible IC cases are summarized in Table 2 .

Information regarding the age of alosetron patients who developed IC was available for 28 patients. Of these 28 patients, those who had experienced probable/possible IC tended to be older, with $68 \%(n=19)$ of cases occurring in patients over 50 years of age. Furthermore, patients over 50 years of age, compared with their younger counterparts, experienced: (a) a longer (delayed) time to onset of IC after initiating alosetron therapy (224 days versus 52 days); (b) a higher prevalence of comorbid illnesses $(53 \%$ versus $44 \%$ ); (c) a greater likelihood of hospitalization for treatment of IC (63\% versus 22\%). Median duration of illness and average total daily dose of alosetron $(1 \mathrm{mg})$ were similar in older and younger patients. 
Table 2. Characteristics, demographics, clinical symptoms, and outcomes for all probable or possible cases of ischemic colitis under the risk management program (November 2002-December 2011).

\begin{tabular}{|c|c|}
\hline Characteristic & Postmarketing cases ( $n=29)$ \\
\hline Median age, years (range) & $55(22-81)$ \\
\hline$\geq 65$ years, $n[\%]$ & $5(17)$ \\
\hline$\geq 50$ years, $n(\%)$ & $19(68)$ \\
\hline Women, $n(\%)$ & $29(100)$ \\
\hline Median time to onset, days (range) & $114(3-2920)$ \\
\hline$\leq 31$ days, $n(\%)$ & $8(28)$ \\
\hline Median duration, days (range) & $6(2-30)$ \\
\hline Alosetron average dose, mg per day (range) & $1(0.25-2)$ \\
\hline \multicolumn{2}{|l|}{ Alosetron dose, mg per day, $n(\%)$} \\
\hline 0.25 & $3(10)$ \\
\hline 0.5 & $5(17)$ \\
\hline 1.0 & $15(52)$ \\
\hline 2.0 & $5(17)$ \\
\hline Not reported & 1 (3) \\
\hline Prior alosetron use, $n[\%]$ & $3(10)$ \\
\hline \multicolumn{2}{|l|}{ Clinical presentation, $n(\%)$} \\
\hline Abdominal pain & $26(90)$ \\
\hline Hematochezia or bloody diarrhea & $24(83)$ \\
\hline Hematochezia or bloody diarrhea with abdominal pain & $21(72)$ \\
\hline Nausea or vomiting & $11(38)$ \\
\hline Constipation & $6(21)$ \\
\hline \multicolumn{2}{|l|}{ Evaluation, $n(\%)$} \\
\hline Colonoscopy & $19(66)$ \\
\hline Sigmoidoscopy & $8(28)$ \\
\hline Computed tomography/X-ray & $12(41)$ \\
\hline Biopsy & $22(76)$ \\
\hline \multicolumn{2}{|l|}{ Concomitant conditions or medications, $n[\%)^{*}$} \\
\hline Any condition or medication use & $22(76)$ \\
\hline Comorbidity & $14(48)$ \\
\hline Concomitant medications & $15(52)$ \\
\hline \multicolumn{2}{|l|}{ Intervention, $n(\%)$} \\
\hline Emergency room visit & $3(10)$ \\
\hline Hospitalization & $14(48)$ \\
\hline Surgery & $1(3)$ \\
\hline \multicolumn{2}{|l|}{ Outcome, $n(\%)$} \\
\hline Symptoms resolved or improved & $29(100)$ \\
\hline \multicolumn{2}{|c|}{$\begin{array}{l}{ }^{*} \text { Concomitant medication (e.g. estrogens, tryptamine-based drugs for the treatment of migraines, nonsteroidal } \\
\text { anti-inflammatory drugs), or condition (e.g. hypertension, endometriosis, diabetes, diverticulitis, vasculitis) with possible } \\
\text { link to ischemic colitis. } \\
\text { Data not reported in all cases. }\end{array}$} \\
\hline
\end{tabular}

Time to onset of probable/possible cases of IC after initiation of alosetron treatment was analyzed for 27 cases of IC for which data were available. Of these cases, $52 \%(n=14)$ occurred within 120 days (early onset) and $48 \%(n=13)$ occurred over 120 days (late onset) after initiation of alosetron. Median IC onset times were
27 days and 805 days for the early-onset and late-onset groups, respectively. Patients with late-onset IC were older than patients with early-onset IC (median age of 56 years versus 52 years). Median duration of IC symptoms was approximately 4 days in patients with earlyonset IC and 8.5 days in those with late-onset 
IC. Early-onset IC patients were more likely to have comorbidities than those with late-onset IC ( $71 \%$ versus $15 \%)$. Hospitalizations occurred twice as often in the early-onset patients than in those with late-onset IC (57\% and $31 \%$, respectively).

Data on duration of IC symptoms were available for 21 patients and divided into categories of 5 days or fewer (short duration, $n=10$ ), and greater than 5 days (long duration, $n=11$ ). Median duration of IC symptoms was 3 days and 14 days for patients with short versus long duration of symptoms, respectively. All 10 patients (100\%) with a short duration of IC had comorbid illnesses or took concomitant medications that may have predisposed them to IC, compared with $64 \%$ of patients with long duration. Patients with a short duration were hospitalized for treatment in $80 \%$ of cases, compared with a hospitalization rate of $27 \%$ for those with IC of long duration. Median age, median time to onset of symptoms, and mean alosetron dose were similar in patients with short versus long duration of IC, respectively: age, 59 years versus 58 years; time to onset, 49 days versus 52 days; average daily dose, $1 \mathrm{mg}$ for both groups.

Three patients $(10 \%)$ had emergency room visits and 14 patients $(48 \%)$ were hospitalized related to IC. The median duration of hospitalization was 3 days, ranging from 1 to 14 days. All but three of the hospitalized patients had hospital stays of 3 days or less. Patients who were hospitalized tended to be older (61 years versus 49 years for patients who were not hospitalized), on concomitant medications or have comorbidities (93\% versus $67 \%$ ), and have a shorter time to onset of IC symptoms (36 days versus 510 days). Median total daily dose of alosetron was similar for hospitalized and nonhospitalized patients (0.9 $\mathrm{mg}$ versus $1.1 \mathrm{mg}$ ).

Of the 14 IC cases that required hospitalization, 1 patient with several comorbidities and concomitant medications required surgery. The patient was a 60 -year-old female with a medical history of IBS-D, which was initially diagnosed 4 years prior to the IC event; other comorbidities were atherosclerotic vascular disease, hyperlipidemia, hypertension, diabetes mellitus, hepatomegaly, kidney disease, peritoneal adhesions, hemorrhoids, obesity, anemia, and arthritis. Approximately 1 month prior to hospitalization, she saw her gastroenterologist complaining of worsening diarrhea, lower abdominal cramping, pain, and urgency, and was subsequently prescribed alosetron $0.5 \mathrm{mg}$ once daily. A few days after initiating therapy, she reported experiencing constipation and was instructed to discontinue alosetron for 3 days and restart at a lower dose. Approximately 2 weeks later, she began experiencing intermittent diarrhea and constipation accompanied by severe abdominal pain and was hospitalized. At the time of hospitalization, the patient's concomitant medications included simvastatin, triamterene/ hydrochlorothiazide, metronidazole, propoxyphene, nabumetone, belladonna/phenobarbital, and hyoscyamine. A surgical procedure was performed and involved an exploratory laparotomy, lysis of adhesions, sigmoidectomy with Hartmann's procedure, and appendectomy with decompression of the colon. Pathological findings were consistent with IC. The patient recovered shortly thereafter and was discharged from the hospital 14 days after admission.

Among the 29 IC cases, there were no deaths, transfusions, or occurrences of mesenteric ischemia reported. Bowel surgery was performed in one case of probable/possible IC, as described. All 29 IC cases either resolved or improved. In general, IC events in the postmarketing period under the RMP were transient, self-limited, and resolved without sequelae (Table 3).

\section{CoC cases}

A total of seven cases, adjudicated as $\mathrm{CoC}$, were found from the alosetron postmarketing safety database. A summary of the demographics, clinical characteristics, and outcomes of these CoC cases is presented in Table 4. These seven confirmed cases of CoC were due to bowel obstruction (four cases), fecal impaction (two cases), and ileus (one case); five cases occurred in women and two in men. Notably, only one case of $\mathrm{CoC}$ has been reported since 2008. The median age of patients with $\mathrm{CoC}$ was 45 years. Median time to onset of CoC symptoms was 23 days, median duration of $\mathrm{CoC}$ events was 2 days, and median total daily dose of alosetron was $2 \mathrm{mg}$. Two patients (29\%) had comorbidities at the onset of $\mathrm{CoC}$, including hypothyroidism and hypokalemia in one patient and diabetes in the other. The first patient's hypothyroidism was being treated with levothyroxine; the second patient with diabetes was taking metformin and sitagliptin. Overall, concomitant medication use was common and included antidepressants or psychotropics $(57 \%, n=4)$, antidiarrheals $(43 \%, n=3)$, and 
Table 3. Comparison of characteristics for cases classified as probable or possible ischemic colitis from postmarketing data before alosetron withdrawal* and after reintroduction.

\begin{tabular}{|c|c|c|}
\hline & $\begin{array}{l}\text { Before June } 2002 \\
\text { (before reintroduction/prior to } \\
\text { risk management program) }\end{array}$ & $\begin{array}{l}\text { November 2002-December } 2011 \\
\text { (reintroduction under the risk } \\
\text { management program) }\end{array}$ \\
\hline Prescribing time span & 10 months & 109 months \\
\hline Gender & 57 female/1 male & 29 female \\
\hline Median age, years (range) & $55(25-80)$ & $55(22-81)$ \\
\hline$\geq 65$ years & $23 \%$ & $17 \%$ \\
\hline Median time to onset, days (range) & $14(0.5-136)$ & $114(3-2920)$ \\
\hline \multicolumn{3}{|l|}{ Presentation } \\
\hline Abdominal pain & $79 \%$ & $90 \%$ \\
\hline $\begin{array}{l}\text { Hematochezia or bloody diarrhea } \\
\text { with abdominal pain }\end{array}$ & $67 \%$ & $72 \%$ \\
\hline Concurrent constipation & $24 \%$ & $21 \%$ \\
\hline \multicolumn{3}{|l|}{ Outcomes } \\
\hline Deaths & $0 \%$ & $0 \%$ \\
\hline Intestinal surgery & $5.2 \%$ & $1.7 \%$ \\
\hline Transfusion & $1.7 \%$ & $0 \%$ \\
\hline Hospitalization & $67 \%$ & $48 \%$ \\
\hline Resolved or improved & $77.5 \%$ & $100 \%$ \\
\hline Unresolved & $7 \%$ & $0 \%$ \\
\hline Unknown & $15.5 \%$ & $0 \%$ \\
\hline
\end{tabular}

narcotic analgesics $(14 \%, n=1)$. A majority of CoC cases $(57 \%, n=4)$ occurred within the first 30 days of alosetron treatment. Two patients $(29 \%)$ had previously been treated with alosetron during the initial marketing period in 2000 without experiencing clinically significant AEs. Five $(71 \%)$ of the CoC cases resulted in hospitalization. All CoC cases for which follow-up information was available (six cases) were confirmed to have resolved. One case was lost to follow up (outcome unknown). No deaths, perforation of the intestine, toxic megacolon, or surgeries were reported in patients with $\mathrm{CoC}$ over the 9-year period of the RMP (Table 5).

\section{Temporal trends in incidence rates of $I C$ and $\mathrm{CoC}$}

The adjudicated incidence rates of probable/ possible IC in alosetron users remained at low levels in the periods before and after the implementation of the RMP (0.96 cases/1000 patientyears versus 1.03 cases/1000 patient-years, respectively [Table 1]). Over the 9-year period of the RMP, the cumulative adjudicated incidence rate of probable/possible IC has continually been low and stable at approximately 1.0 case/1000 patient-years (Figure 1). Analysis of
AE reports from the alosetron safety database of abdominal pain accompanied by hematochezia/ bloody diarrhea, symptoms that may strongly indicate a case of IC, shows a decline in these AEs under the RMP (Figure 2). The reported incidence rate of abdominal pain with hematochezia/bloody diarrhea decreased seven-fold from 2003 to 2011.

In contrast to IC, the adjudicated incidence rate of $\mathrm{CoC}$ in alosetron patients has declined considerably under the RMP compared with the rate prior to reintroduction. The adjudicated incidence rate of $\mathrm{CoC}$ cases prior to reintroduction was 0.59 cases $/ 1000$ patient-years, compared with a rate of 0.25 cases $/ 1000$ patient-years after reintroduction under the RMP (Table 1). Of the seven cases of $\mathrm{CoC}$ since reintroduction, six occurred from 2002 through 2007, with one case reported from 2008 through 2011. During the 9-year period of the RMP, the cumulative adjudicated incidence rate of $\mathrm{CoC}$ has been low, and has progressively declined over time (Figure 3 ). This reduction in the adjudicated incidence rate of $\mathrm{CoC}$ has been paralleled by a marked decrease (8.5-fold) in reports of AEs of constipation under the RMP (Figure 2). 
Table 4. Characteristics, demographics, clinical symptoms, and outcomes for complications of constipation under the risk management program (November 2002-December 2011).

\begin{tabular}{|c|c|}
\hline Characteristic & Postmarketing cases $(n=7)$ \\
\hline Median age, years (range) & $45(27-82)$ \\
\hline$\geq 65$ years, $n(\%)$ & $1(14)$ \\
\hline$\geq 50$ years, $n(\%)$ & $2(29)$ \\
\hline Female & $5(71)$ \\
\hline Median time to onset, days (range) & $22.5(3-87)$ \\
\hline$\leq 31$ days, $n(\%)$ & $4(57)$ \\
\hline Median duration, days (range) & $2(0.25-3)$ \\
\hline Alosetron average dose, mg per day (range) & $2(1-4)$ \\
\hline \multicolumn{2}{|l|}{ Alosetron dose, mg per day, $n(\%)$} \\
\hline 0.25 & 0 \\
\hline 0.5 & 0 \\
\hline 1.0 & $2(29)$ \\
\hline 2.0 & 2 (29) \\
\hline 4.0 & $1(14)$ \\
\hline Not reported & 2 (29) \\
\hline Prior alosetron use, $n(\%)$ & 2 (29) \\
\hline \multicolumn{2}{|l|}{ Clinical presentation, $n(\%)$} \\
\hline Abdominal pain & $3(43)$ \\
\hline Nausea or vomiting & 2 (29) \\
\hline Diarrhea & 2 (29) \\
\hline \multicolumn{2}{|c|}{ Medical conditions or concomitant medications, cases $(\%)^{*}$} \\
\hline Any condition or medication use & $5(71)$ \\
\hline Hypothyroidism\$ & $1(14)$ \\
\hline Hypokalemia\$ & $1(14)$ \\
\hline Diabetes & $1(14)$ \\
\hline Antidiarrheals & $3(43)$ \\
\hline Antidepressants/psychotropics & $4(57)$ \\
\hline Narcotics & $1(14)$ \\
\hline \multicolumn{2}{|l|}{ Intervention, $n[\%]$} \\
\hline Emergency room visit & $1(14)$ \\
\hline Hospitalization & $5(71)$ \\
\hline \multicolumn{2}{|l|}{ Outcome, $n(\%)$} \\
\hline Symptoms resolved or improved & $6(86 \%)$ \\
\hline Unknown & $1(14)$ \\
\hline \multicolumn{2}{|c|}{$\begin{array}{l}\text { *Concomitant medications or medical conditions associated with constipation. } \\
\text { \$Hypothyroidism and hypokalemia occurred in the same patient. } \\
\text { Data not reported in all cases. }\end{array}$} \\
\hline
\end{tabular}

\section{Discussion}

The current study demonstrates the stable and decreasing incidence rates over time of adjudicated cases of IC and CoC, respectively, associated with alosetron since implementation of the RMP. Since the previous study [Chang et al. 2010], this analysis contributes an additional 3.5 years of postmarketing safety data, which corresponds to approximately 11,300 patient-years, and amounts to an overall total of 28,084 patient-years of exposure to alosetron therapy. These data are important as there are limited published data on the postmarketing safety and corresponding clinical outcomes associated with therapeutic agents, particularly those under a RMP, over a relatively long period of time.

Temporal trends over the 9 years of the alosetron RMP demonstrate that incidence rates of probable/possible IC and $\mathrm{CoC}$ remain rare. The 
Table 5. Comparison of characteristics for cases classified as complication of constipation from postmarketing data before alosetron withdrawal* and after reintroduction.

\begin{tabular}{lcc} 
& $\begin{array}{l}\text { Before June 2002 (before } \\
\text { reintroduction/prior to risk } \\
\text { management program) }\end{array}$ & $\begin{array}{l}\text { November 2002-December } \\
2011 \text { (reintroduction under the } \\
\text { risk management program) }\end{array}$ \\
\hline Prescribing time span & 10 months & 109 months \\
Gender & 53 female/5 male & 5 female/2 male \\
Median age, years (range) & $51(20-82)$ & $45(27-82)$ \\
$\geq 65$ years & $26 \%$ & $14 \%$ \\
Median time to onset, days (range) & $14(1-180)$ & $2313-87)$ \\
Complication & $15.5 \%$ & $0 \%$ \\
Perforation of the intestine & $3.4 \%$ & $0 \%$ \\
Toxic megacolon & $46.6 \%$ & $57.1 \%$ \\
Obstruction & $5.2 \%$ & $14.3 \%$ \\
Ileus & $29.3 \%$ & $28.6 \%$ \\
Fecal impaction & & $0 \%$ \\
Outcomes & $3.4 \%$ & $0 \%$ \\
Deaths & $19 \%$ & $0 \%$ \\
Intestinal/anorectal surgery & $3.4 \%$ & $0 \%$ \\
Disimpaction & $60.3 \%$ & $86 \%$ \\
Hospitalization & $13.8 \%$ & $14 \%$ \\
Emergency room & $82.8 \%$ & $0 \%$ \\
Resolved or improved & $0 \%$ & \\
Unresolved & $13.8 \%$ & \\
Unknown & & \\
\hline *Data for period before withdrawal [FDA, 2002]. & \\
\hline
\end{tabular}

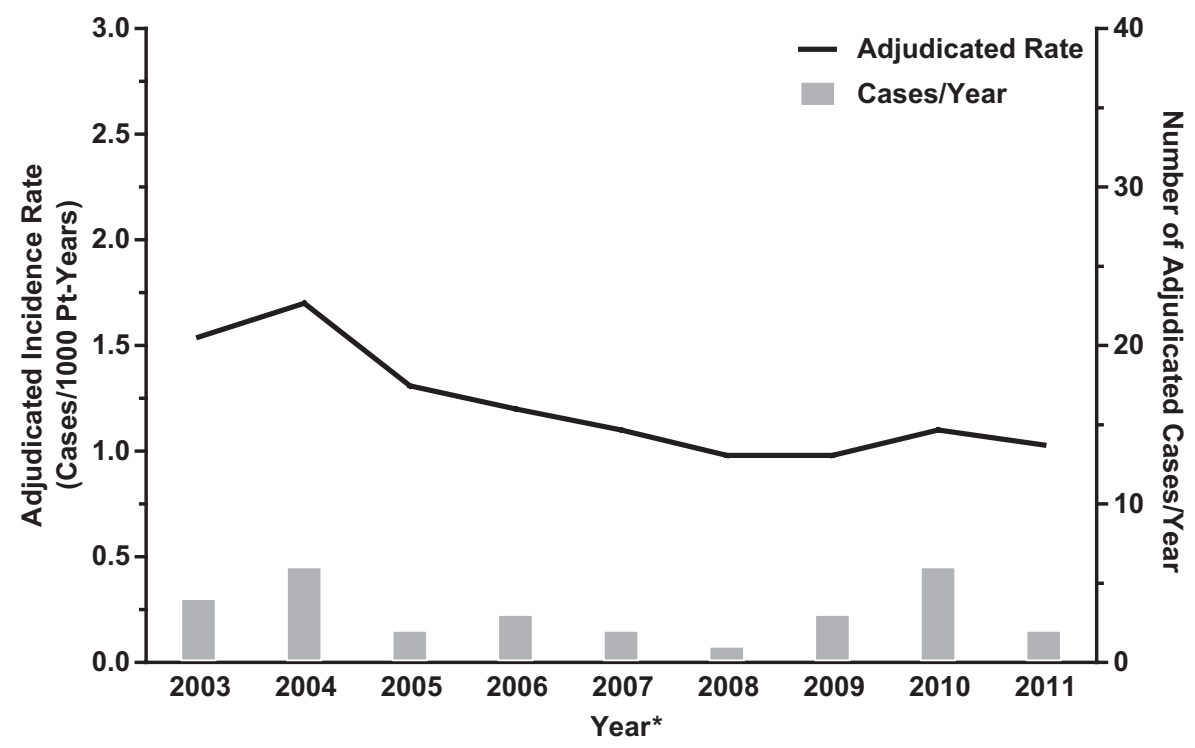

Figure 1. Annual number of adjudicated ischemic colitis cases under the risk management program and cumulative adjudicated incidence rate of ischemic colitis (November 2002-December 2011).

*IC data for 2002 was collected for 6 weeks only (20 November to 31 December) and are combined with 2003 data.

adjudicated incidence rate of IC has been stable at approximately 1.0 cases $/ 1000$ patient-years, which is similar to the inherent background rate of IC in IBS patients that ranges from 0.40 cases $/ 1000$ patient-years to 1.79 cases $/ 1000$ patient-years [Cole et al. 2004; Walker et al. 2004; 


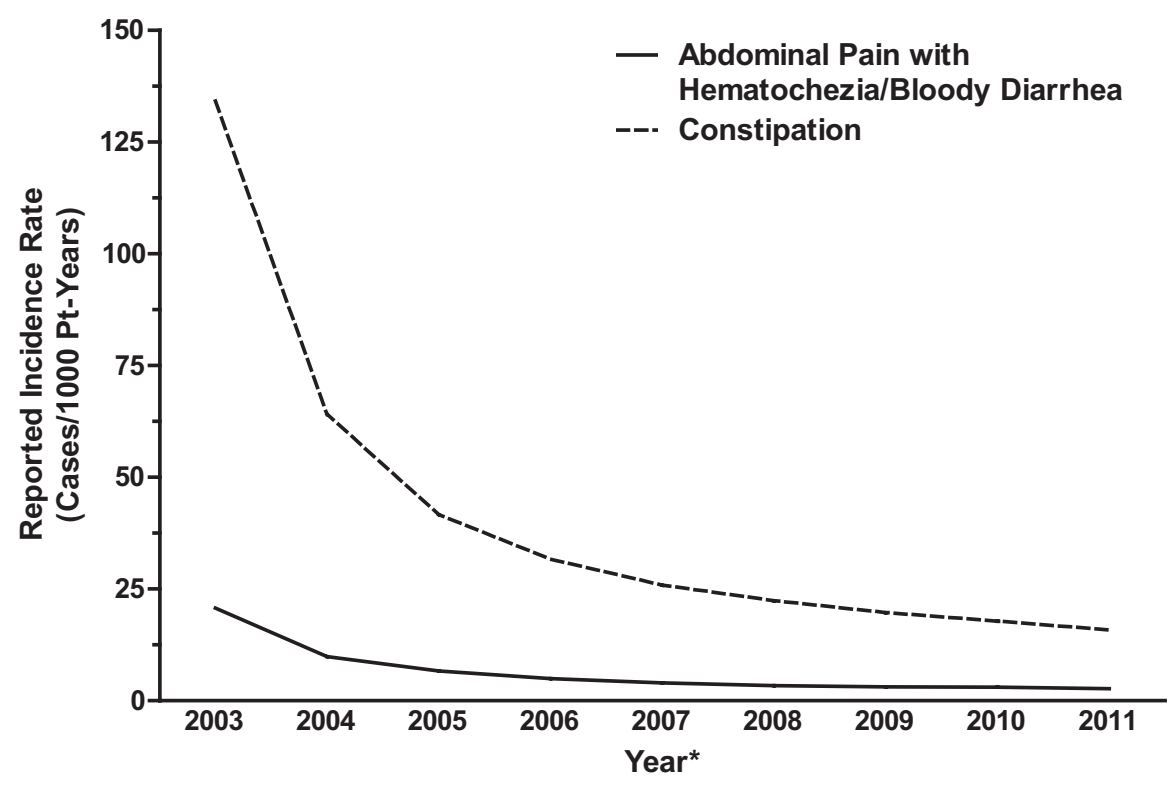

Figure 2. Cumulative reported incidence rates of clinically relevant adverse events potentially indicative of ischemic colitis or complications of constipation over the 9-year period of the risk management program.

* Adverse event data for 2002 was collected for 6 weeks only (20 November to 31 December) and are combined with 2003 data.

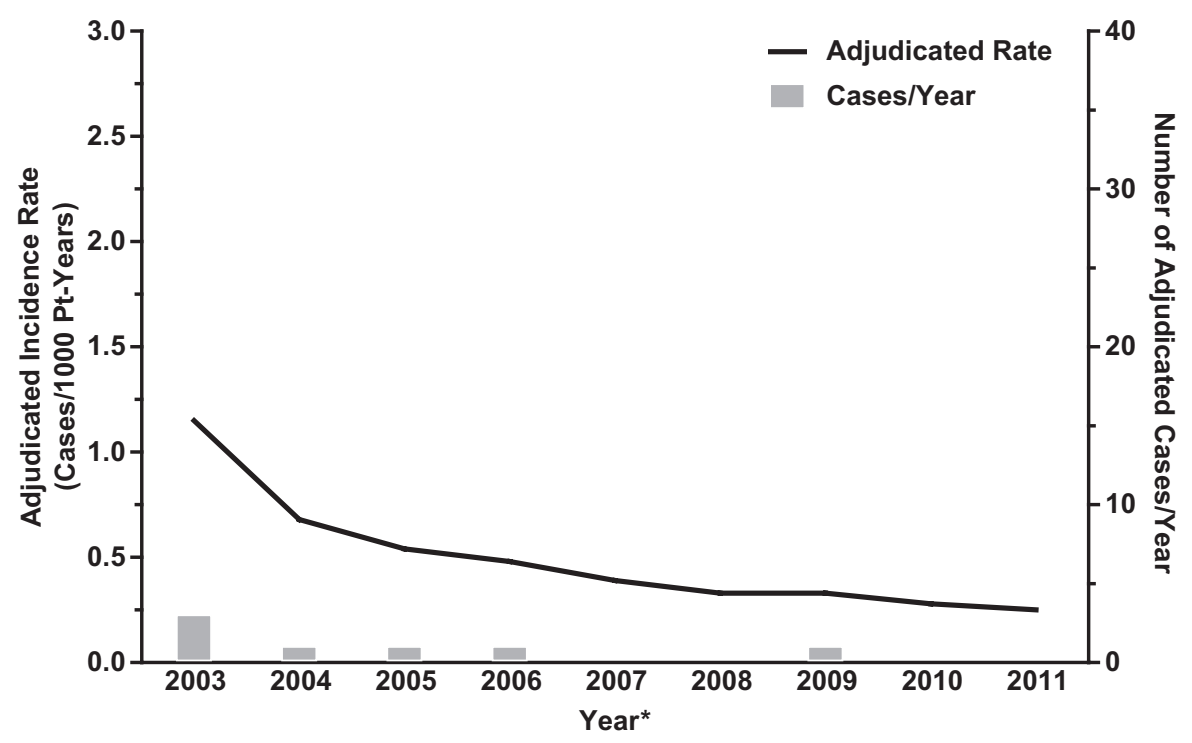

Figure 3. Annual number of adjudicated complications of constipation cases under the risk management program and cumulative adjudicated incidence rate of complications of constipation (November 2002-December 2011).

*CoC data for 2002 was collected for 6 weeks only (20 November to 31 December) and are combined with 2003 data.

Singh et al. 2004]. Epidemiological studies have consistently demonstrated that IBS itself is an independent risk factor for IC, and have shown that patients with IBS have a two- to four-fold greater risk of developing IC than those without IBS [Walker et al. 2004; Hervé et al. 2009; Chang et al. 2008]. Given the apparent increased background rate of IC among patients with IBS, the frequency of IC attributable to alosetron in the real-world, clinical practice setting remains difficult to determine. The annual number of probable/possible cases of IC observed has been few, although there is considerable variability from year to year ranging from one case in 2008 to six cases in 2004 and 2010 . The high variability in the annual number of IC cases may be reflective 
of the idiopathic nature of IC due to multiple pathophysiologic factors (e.g. age, comorbidities, concomitant medications, surgical history, etc.) that potentially contribute to its development [Chang et al. 2008; Brandt and Boley, 2000; Hass et al. 2007]. Considering the epidemiological evidence to date with IC, IBS, and alosetron, another possibility is that the incidence rate of IC with alosetron is reflective of the background rate of IC in IBS patients. However, more rigorous casecontrol studies in IBS patients would be required to investigate this hypothesis.

Exploratory analyses of patient demographics and medical histories during the 9-year period since reintroduction suggest potential risk factors for the development of IC. Age appears to be a factor in the occurrence of IC in alosetron users, with $68 \%$ of cases occurring in patients older than 50 years. The median age of alosetron patients with probable/possible IC was 55 years, both prior to reintroduction and postreintroduction to the US market. Moreover, approximately half of patients with IC were taking concomitant medication $(52 \%)$, or had concurrent medical conditions $(48 \%)$ with possible links to IC [Cole et al. 2004; Zervoudis et al. 2008; Deana and Dean, 1995; Preventza et al. 2001; Charles et al. 2005; Schwartz and Smith, 2004; Knudsen et al. 1998; Radaelli et al. 2005; Thiéfin and Beaugerie, 2005; Gandhi et al. 1996; Matsumoto et al. 1994]. These factors were also higher in patients with IC who were hospitalized compared with those who were not. These findings are consistent with previous reports on IC and have been observed in patients treated with alosetron, as well as in the general IBS population, which implies that these risk factors are likely nonspecific [Chang et al. 2006, 2008, 2010; Cole et al. 2004; Walker et al. 2004; Hervé et al. 2009; Brandt and Boley, 2000; Hass et al. 2007; Sotiriadis et al. 2007; Longstreth and Yao, 2009; Lewis, 2010; Suh et al. 2007]. The relationship between alosetron use in IBS patients, concomitant medications or comorbidities, and incidence of IC, however, remains unclear and warrants further elucidation.

Most cases of IC observed after the implementation of the RMP were self-limited and all resolved or improved after discontinuation of alosetron. An overall decrease of $19 \%$ in the number of probable/possible IC cases that required hospitalization was seen since reintroduction under the RMP ( $48 \%$ versus $67 \%$ prior to reintroduction).
In addition, there has been a lower percentage of cases requiring intestinal surgery $(1.7 \%$ versus $5.2 \%)$, no cases requiring transfusions $(0 \%$ versus $1.7 \%)$, and a greater proportion of cases that resolved or improved (100\% versus $77.5 \%)$. There was only one IC case that required intestinal surgery since the RMP was introduced. The patient had several risk factors for IC including older age, multiple comorbidities, and use of several concomitant medications.

In contrast to the relatively stable incidence of IC, the incidence rate of adjudicated $\mathrm{CoC}$ cases in the postmarketing alosetron population has decreased by $58 \%$ since the RMP was implemented. Since the reintroduction of alosetron in 2002, the number of adjudicated cases of $\mathrm{CoC}$ has averaged less than one per year. With the exception of the three cases in 2003, there were either single or no cases annually from 2004 to 2011, and no cases since 2009. There have been no deaths, surgeries, toxic megacolon, or intestinal perforations in adjudicated cases of CoC. Five of seven patients $(71 \%)$ with $\mathrm{CoC}$ were taking concomitant medications and two patients $(29 \%)$ had concurrent conditions associated with constipation (i.e. hypothyroidism and type 2 diabetes). Although medications and medical conditions have been associated with constipation, the exact influence of these factors with regard to CoC remain unclear [van Dijk et al. 1998; Locke et al. 2000; Shafer et al. 1984; Sartoretti et al. 1996; Vinik et al. 2003]. The use of lower doses of alosetron and cautious evaluation of any potential AEs related to constipation likely has decreased incidences of both constipation and CoC.

Importantly, while annual prescribing of alosetron under the RMP increased 35\% from 2003 (31,645 prescriptions) to 2011 (42,701 prescriptions) (from Source ${ }^{\circledR}$ Prescriber database), adjudicated incidence rates of IC and $\mathrm{CoC}$ have remained rare, and reported incidence rates of clinically related AEs (i.e. abdominal pain with hematochezia/bloody diarrhea and constipation) have declined 7 - to 8.5 -fold. These data strongly suggest that increased prescriber and patient education on the signs and symptoms of IC, CoC, and constipation resulting in early recognition and clinical management of potentially serious AEs, as intended by the RMP, may be a reason for these observed decreases in adjudicated and reported incidence rates. Furthermore, this analysis demonstrates that the vast majority of 
reported cases of abdominal pain with hematochezia/bloody diarrhea or constipation was not due to confirmed cases of IC or CoC, as evidenced by the large discrepancies between adjudicated IC or CoC cases and reported presenting symptoms.

Certain limitations and strengths are associated with the use of postmarketing AE data. General limitations include the potential for underreporting of $\mathrm{AE}$ data owing to the fact that $\mathrm{AE}$ reporting is voluntary for healthcare professionals, the lack of certainty in determining whether an $\mathrm{AE}$ is caused by the drug or due to the underlying disease and/or concomitant medications, the high variability in the amount and quality of information contained in postmarketing $\mathrm{AE}$ reports, and the inability to estimate accurately the denominator for incidencerate calculations [Goldman, 1998; Fletcher, 1991; Begaud et al. 1994]. In this study, alosetron exposure was calculated from prescription data based on the assumption that all prescriptions represented 1 month of alosetron use, when in fact, the specific duration of alosetron use for each patient was unknown. Additionally, bias and fluctuations in AE-reporting rates over time may be attributed to educational activities and/or regulatory actions (e.g. medical education lectures and publications, and FDA-mandated AE notifications), which raise awareness and can increase reporting rates [WeissSmith et al. 2011; Weber, 1984].

The strengths of postmarketing $\mathrm{AE}$ data include the possibility for early detection of potential safety signals, identification of rare AEs not previously identified in controlled conditions such as clinical trials, and the ability to evaluate realworld use and clinical outcomes [Goldman, 1998; Fletcher, 1991]. Furthermore, under the alosetron RMP, serious AEs are required to be reported by the enrolled physicians, and pharmaceutical manufacturers of FDA-approved drugs and biologics are required by law to monitor and report AEs [FDA, 2012].

It is likely that the increased awareness, and prompt recognition and treatment of these AEs resulting from physician training and patient education as intended by the RMP have contributed to mitigating the serious outcomes of IC and CoC associated with the use of alosetron. The possibility that the RMP is enabling prescribers to better identify appropriate patients for alosetron and facilitate recognition of symptoms associated with IC and $\mathrm{CoC}$ is supported by the decline in reported incidence rates of abdominal pain accompanied by hematochezia or bloody diarrhea and constipation, respectively, as seen over the entire 9-year period of the RMP (Figure 2). Consistent with these data, results from several analyses of the alosetron patient follow-up survey have also indicated that most patients met or exceeded the clinical criteria for severe IBS-D, were well informed of the risks and benefits of alosetron use, and were highly compliant with the elements of the RMP over time [Miller et al. 2006; Nicandro et al. 2012; Tennis et al. 2007]. The additional postmarketing safety data presented in the current study, coupled with previous evidence of the high level of compliance with the various elements of the RMP, suggest that the alosetron RMP is achieving its objective of appropriately balancing the risks and benefits of alosetron therapy.

In summary, the present analysis shows that among alosetron patients treated during the 9 years since reintroduction under the RMP, the overall adjudicated incidence rate of IC cases has remained rare and stable, while the adjudicated incidence rate of $\mathrm{CoC}$ cases has sharply decreased compared with the period before withdrawal. Under the alosetron RMP, the number of serious outcomes of IC has decreased, with no transfusions or deaths. A dramatic and progressive decline in the rate of $\mathrm{CoC}$ cases has occurred, with no serious outcomes of CoC (including perforations, surgeries, or deaths). Decreases in the reported incidence rates of clinically relevant symptoms potentially indicative of IC (abdominal pain with hematochezia or bloody diarrhea) and $\mathrm{CoC}$ (constipation) were also observed. Appropriate patient selection along with a high degree of physician and patient compliance with the various elements of the RMP appear to have resulted in mitigating the AEs and serious outcomes associated with IC and $\mathrm{CoC}$ over the 9 years of alosetron use under the RMP.

\section{Acknowledgements}

Medical writing support, funded by Prometheus Laboratories Inc., was provided by Mark Goldschlag and Anthony Stonehouse. Dr Stonehouse is an employee of Watson \& Stonehouse Enterprises, LLC.

\section{Funding}

This study was funded by Prometheus Laboratories Inc. The preparation of this paper was funded by Prometheus Laboratories Inc. 


\section{Conflict of interest statement}

$\mathrm{KT}$ is principal at Medical Affairs 360 and serves as a consultant to Prometheus Laboratories Inc. JPN is an employee of Prometheus Laboratories Inc. RS and EC are former employees of Prometheus Laboratories Inc. EC is currently an employee of Nestlé Health Science. LC has served as a member of an advisory board for Prometheus Laboratories Inc.

\section{References}

Begaud, B., Moride, Y., Tubert-Bitter, P., Chaslerie, A. and Haramburu, F. (1994) False-positives in spontaneous reporting: should we worry about them? Br f Clin Pharmacol 38: 401-404.

Brandt, L. and Boley, S. (2000) AGA technical review on intestinal ischemia. Gastroenterology 118: 954-968.

Camilleri, M., Chey, W., Mayer, E., Northcutt, A., Heath, A., Dukes, G. et al. (2001) A randomized controlled clinical trial of the serotonin type 3 receptor antagonist alosetron in women with diarrheapredominant IBS. Arch Intern Med 161: 1733-1740.

Camilleri, M., Northcutt, A., Kong, S., Dukes, G., McSorley, D. and Mangel, A. (2000) Efficacy and safety of alosetron in women with irritable bowel syndrome: a randomised, placebo-controlled trial. Lancet 355: 1035-1040.

Chang, L., Chey, W., Harris, L., Olden, K., Surawicz, C. and Schoenfeld, P. (2006) Incidence of ischemic colitis and serious complications of constipation among patients using alosetron: systematic review of clinical trials and post-marketing surveillance data. Am $\mathcal{F}$ Gastroenterol 101: 1069-1079.

Chang, L., Kahler, K., Sarawate, C., Quimbo, R. and Kralstein, J. (2008) Assessment of potential risk factors associated with ischaemic colitis.

Neurogastroenterol Motil 20: 36-42.

Chang, L., Tong, K. and Ameen, V. (2010) Ischemic colitis and complications of constipation associated with the use of alosetron under a risk management plan: clinical characteristics, outcomes, and incidences. Am $\mathcal{F}$ Gastroenterol 105: 866-875.

Charles, J., Pullicino, P., Stoopack, P. and Shroff, Y. (2005) Ischemic colitis associated with naratriptan and oral contraceptive use. Headache 45: 386-389.

Chey, W., Chey, W., Heath, A., Dukes, G., Carter, E., Northcutt, A. et al. (2004) Long-term safety and efficacy of alosetron in women with severe diarrhea-predominant irritable bowel syndrome. Am $\mathcal{F}$ Gastroenterol 99: 2195-2203.

Cole, J., Cook, S., Sands, B., Ajene, A., Miller, D. and Walker, A. (2004) Occurrence of colon ischemia in relation to irritable bowel syndrome. $A m \mathcal{F}$ Gastroenterol 99: 486-491.

Deana, D. and Dean, P. (1995) Reversible ischemic colitis in young women. Association with oral contraceptive use. Am f Surg Pathol 19: 454-462.

FDA (2002) Briefing Document for the foint Gastrointestinal Drugs Advisory Committee and Drug Safety and Risk Management Subcommittee, Background Package, 23 April 2002. Silver Spring, MD: US Department of Health and Human Services, Food and Drug Administration. [Available at: http://www. fda.gov/ohrms/dockets/ac/02/briefing/3848B1_02_ FDA\%20Lotronex.pdf; accessed 8 February 2013]

FDA (2005) Guidance for Industry: Development and Use of Risk Minimization Action Plans. Rockville, MD: US Department of Health and Human Services, Food and Drug Administration, Center for Drug Evaluation and Research, Center for Biologics Evaluation and Research. [Available at: http://www.fda.gov/downloads/Drugs/ GuidanceComplianceRegulatoryInformation/ Guidances/ucm071616.pdf; accessed 8 February 2013]

FDA (2012) Postmarketing Reporting of Adverse Drug Experiences. Federal Regulation (FDA 21 CFR 314.80); revised 1 April 2012. Silver Spring, MD: US Department of Health and Human Services, Food and Drug Administration. [Available at: http://www. accessdata.fda.gov/scripts/cdrh/cfdocs/cfcfr/ CFRSearch.cfm?fr=314.80; accessed 8 February 2013]

FDA (2013) Approved Risk Evaluation and Mitigation Strategies (REMS). Silver Spring, MD: US Department of Health and Human Services, Food and Drug Administration. [Available at: http://www.fda.gov/Drugs/DrugSafety/ PostmarketDrugSafetyInformationforPatients andProviders/ucm 111350.htm; accessed 8 February 2013]

Fletcher, A. (1991) Spontaneous adverse drug reaction reporting versus event monitoring: a comparison. F $R$ Soc Med 84: 341-344.

Gandhi, S., Hanson, M., Vernava, A., Kaminski, D. and Longo, W. (1996) Ischemic colitis. Dis Colon Rectum 39: 88-100.

Goldman, S. (1998) Limitations and strengths of spontaneous reports data. Clin Ther 20(Suppl. C): C40-C44.

Hass, D., Kozuch, P. and Brandt, L. (2007) Pharmacologically mediated colon ischemia. Am $\mathcal{F}$ Gastroenterol 102: 1765-1780.

Hervé, S., Beaugerie, L., Bouhnik, Y., Savoye, G., Colombel, J., Dyard, F. et al. (2009) Irritable bowel syndrome is more frequent in patients hospitalized 
for ischaemic colitis: results of a case-control study. Neurogastroenterol Motil 21: 1170-e102.

Knudsen, J., Friedman, B., Chen, M. and Goldwasser, J. (1998) Ischemic colitis and sumatriptan use. Arch Intern Med 158: 1946-1948.

Krause, R., Ameen, V., Gordon, S., West, M., Heath, A., Perschy, T. et al. (2007) A randomized, doubleblind, placebo-controlled study to assess efficacy and safety of $0.5 \mathrm{mg}$ and $1 \mathrm{mg}$ alosetron in women with severe diarrhea-predominant IBS. Am $\mathcal{F}$ Gastroenterol 102: 1709-1719.

Lembo, A., Olden, K., Ameen, V., Gordon, S., Heath, A. and Carter, E. (2004) Effect of alosetron on bowel urgency and global symptoms in women with severe, diarrhea-predominant irritable bowel syndrome: analysis of two controlled trials. Clin Gastroenterol Hepatol 2: 675-682.

Lewis, J. (2010) Alosetron for severe diarrheapredominant irritable bowel syndrome: safety and efficacy in perspective. Expert Rev Gastroenterol Hepatol 4: 13-29.

Locke, G. III, Pemberton, J. and Phillips, S. (2000) AGA technical review on constipation. Gastroenterology 118: 1766-1778.

Longstreth, G. and Yao, J. (2009) Epidemiology, clinical features, high-risk factors, and outcome of acute large bowel ischemia. Clin Gastroenterol Hepatol 7: 1075-1080.

Matsumoto, T., Iida, M., Kimura, Y., Nanbu, T. and Fujishima, M. (1994) Clinical features in young adult patients with ischaemic colitis. $\mathcal{F}$ Gastroenterol Hepatol 9: 572-575.

Miller, D., Bennett, L., Hollis, K., Tennis, P., Cook, S. and Andrews, E. (2006) A patient follow-up survey programme for alosetron: assessing compliance to and effectiveness of the risk management programme. Aliment Pharmacol Ther 24: 869-878.

Nicandro, J., Shin, P. and Chuang, E. (2012)

Evaluation of treatment continuation with alosetron by IBS-D severity criteria. Curr Med Res Opin 28: 449-456.

Preventza, O., Lazarides, K. and Sawyer, M. (2001) Ischemic colitis in young adults: a single-institution experience. F Gastrointest Surg 5: 388-392.

Prometheus Laboratories Inc. (2010) LOTRONEX ${ }^{\circledR}$ (alosetron hydrochloride) prescribing information. [Available at: https://www.lotronex.com/_docs/ Lotronex_PI.pdf; last updated September 2010; accessed 8 February 2013]

Radaelli, F., Feltri, M., Meucci, G., Spinzi, G., Terruzzi, V. and Minoli, G. (2005) Ischemic colitis associated with rofecoxib. Dig Liver Dis 37: 372-376.

Sartoretti, C., Sartoretti, S., DeLorenzi, D. and Buchmann, P. (1996) Intestinal non-rotation and pseudo obstruction in myotonic dystrophy: case report and review of the literature. Int $\mathcal{F}$ Colorectal Dis 11: 10-14.

Schwartz, D. and Smith, D. (2004) Colonic ischemia associated with naratriptan use. $\mathcal{F}$ Clin Gastroenterol 38: 790-792.

Shafer, R., Prentiss, R. and Bond, J. (1984)

Gastrointestinal transit in thyroid disease.

Gastroenterology 86: 852-855.

Singh, G., Mithal, A. and Triadafilopoulos, G. (2004) Patients with irritable bowel syndrome have a highrisk of developing ischemic colitis [abstract no. 349]. Gastroenterology 126(4 Suppl. 2): A41.

Sotiriadis, J., Brandt, L., Behin, D. and Southern, W. (2007) Ischemic colitis has a worse prognosis when isolated to the right side of the colon. $A m \mathcal{F}$ Gastroenterol 102: 2247-2252.

Suh, D., Kahler, K., Choi, I., Shin, H., Kralstein, J. and Shetzline, M. (2007) Patients with irritable bowel syndrome or constipation have an increased risk for ischaemic colitis. Aliment Pharmacol Ther 25: 681-692.

Tennis, P., Andrews, E., Hickman, P., Miller, D., Hollis, K. and Cook, S. (2007) The relationship between dosing of alosetron and discontinuation patterns reported by patients participating in a follow-up programme. Aliment Pharmacol Ther 25: 317-322.

Thiéfin, G. and Beaugerie, L. (2005) Toxic effects of nonsteroidal antiinflammatory drugs on the small bowel, colon, and rectum. Foint Bone Spine 72: 286-294.

van Dijk, K., de Vries, C., van den Berg, P., Dijkema, A., Brouwers, J. and de Jong-van den Berg, L. (1998) Constipation as an adverse effect of drug use in nursing home patients: an overestimate. $\mathrm{Br} F \mathrm{Clin}$ Pharmacol 46: 225-261.

Vinik, A., Maser, R., Mitchell, B. and Freeman, R. (2003) Diabetic autonomic neuropathy. Diabetes Care 26: 1553-1579.

Walker, A., Bohn, R., Cali, C., Cook, S., Ajene, A. and Sands, B. (2004) Risk factors for colon ischemia. Am $\mathcal{F}$ Gastroenterol 99: 1333-1337.

Weber, J. (1984) Epidemiology of adverse reactions to non-steroidal anti-inflammatory drugs. In: Rainsford, K. and Velo, G. (eds), Advances in Inflammation Research. Raven Press: New York.

Weiss-Smith, S., Deshpande, G., Chung, S. and Gogolak, V. (2011) The FDA drug safety surveillance program: adverse event reporting trends. Arch Intern Med 171: 591-593.

Zervoudis, S., Grammatopoulos, T., Iatrakis, G., Katsoras, G., Tsionis, C., Diakakis, I. et al. (2008) Ischemic colitis in postmenopausal women taking hormone replacement therapy. Gynecol Endocrinol 24: 257-260.
Visit SAGE journals online http://tag.sagepub.com

@SAGE journals 